\title{
A IMPORTÂNCIA DA LÍNGUA DE SINAIS PARA O ALUNO SURDO NA EDUCAÇÃO BILÍNGUE: ESTUDO DE CASO
}

\section{THE IMPORTANCE OF THE SIGN LANGUAGE FOR DEAF IN BILINGUAL EDUCATION: CASE STUDY}

\section{LA IMPORTANCIA DEL LENGUAJE SEÑAL PARA SURDOS EN LA EDUCACIÓN BILINGUE: ESTUDIO DE CASO}

\author{
Michelle Bruna Bilecki Mestre \\ Especialista em Educação Especial com ênfase em Deficiência Auditiva/Surdez pela \\ Faculdade de Ciências. Universidade Estadual Paulista Júlio de Mesquita Filho. Bauru, São \\ Paulo, Brasil. Campus Bauru. \\ E-mail: brunabilecki@gmail.com \\ Ana Paula Pacheco Moraes Maturana \\ Programa de Pós-Graduação em Psicologia do Desenvolvimento e Aprendizagem. Faculdade \\ de Ciências. Universidade Estadual Paulista Júlio de Mesquita Filho. Bauru, São Paulo, \\ Brasil. Campus Bauru. \\ E-mail: paula.psico@hotmail.com
}

\begin{abstract}
RESUMO
Levando em conta as afirmativas suscitadas pela temática da inclusão do aluno Surdo e do Bilinguismo o presente trabalho tem por objetivo principal verificar a importância da aprendizagem e aquisição da língua de sinais para o aluno surdo no contexto da escola bilíngue. Foi realizada uma pesquisa em uma Escola de Educação Bilíngue na cidade de São Paulo, através de observações e um questionário aplicado à professora cujas aulas foram observadas. Elas ocorreram em duas turmas do Ensino Fundamental I, sendo uma do sexto ano e outra do oitavo, nas aulas de Língua Portuguesa. Os participantes são todos alunos surdos. A análise foi pautada no referencial teórico desse trabalho. Os resultados apontaram para a necessidade que o aluno surdo tenha acesso a língua o mais cedo possível e para isso ele precisa estar em um ambiente bilíngue, pois sem a língua, a linguagem torna-se rasa, e algumas vezes deturpada. É necessário a língua e o bilinguismo para que o aluno com surdez tenha condições de se desenvolver, proporcionando uma educação de qualidade.
\end{abstract}

Palavras-chave: Surdez. Língua de Sinais. Educação Bilíngue.

\section{ABSTRACT}

Taking into account the affirmations raised by the theme of inclusion of the Deaf student and Bilingualism, the main objective of this study is to verify the importance of learning and acquisition of sign language for the deaf student in the context of the bilingual school. A research was carried out at a School of Bilingual Education in the city of São Paulo, through observations and a questionnaire applied to the teacher whose classes were observed. They occurred in two classes of Elementary School I, being one of the sixth year and another of the 
eighth, in Portuguese Language classes. The participants are all deaf students. The analysis was based on the theoretical framework of this work. The results pointed to the need for the deaf student to have access to the language as soon as possible and for this he needs to be in a bilingual environment, because without language, language becomes shallow, and sometimes misrepresented. Language and bilingualism are necessary for the deaf student to develop, providing a quality education.

Keywords: Deafness. Sign language. Bilingual Education.

\section{RESUMEN}

El presente trabajo tiene como objetivo principal verificar la importancia del aprendizaje y adquisición de la lengua de signos para el alumno sordo en el contexto de la escuela bilingüe. Se realizó una investigación en una Escuela de Educación Bilingüe en la ciudad de São Paulo, a través de observaciones y un cuestionario aplicado a la profesora cuyas aulas fueron observadas. Ellas ocurrieron en dos clases de la Enseñanza Fundamental I, siendo una del sexto año y otra del octavo, en las clases de Lengua Portuguesa. Los participantes son todos alumnos sordos. El análisis fue pautado en el referencial teórico de ese trabajo. Los resultados apuntaron a la necesidad que el alumno sordo tenga acceso a la lengua lo antes posible y para ello él necesita estar en un ambiente bilingüe, pues sin la lengua, el lenguaje se vuelve rasa, y algunas veces distorsionada. Es necesario la lengua y el bilingüismo para que el alumno con sordera tenga condiciones de desarrollarse, proporcionando una educación de calidad.

Palabras clave: Surdez. Lengua de signos. Educación Bilingue.

\section{INTRODUÇÃO}

Sabe-se da importância de receber, acolher e proporcionar uma educação de qualidade a todos. Logo, isso inclui o aluno com deficiência, transtornos globais do desenvolvimento e altas habilidades/superdotação, conhecidos como alunos público alvo da educação especial (PAEE) assim como todos os demais, numa perspectiva de educação de qualidade para todos.

De acordo com as Diretrizes Nacionais para a Educação Especial na Educação Básica, instituídas pela Resolução n 02/2001, “a educação especial deve ocorrer em todas as instituições escolares, etapas e modalidades previstos na LDBEN, de modo a propiciar o pleno desenvolvimento das potencialidades [...]" (BRASIL, 2001). Nesse contexto, a escola deve preparar-se de modo que ela possa se ajustar as necessidades de todos os seus educandos e não o contrário.

Diante disso, é fundamental compreender que durante muito tempo a comunidade Surda lutou por uma educação que os atenda dentro de um ambiente que compreenda suas especificidades, que são as escolas de educação bilíngue. De acordo com o decreto $\mathrm{n}^{\circ} 5.626$, de 22 de dezembro de 2005 (BRASIL, 2005) que regulamenta a Lei ${ }^{\circ} 10.436$, de 24 de abril 
de 2002 (BRASIL, 2002), assegura-se que o Surdo ${ }^{1}$ aprenda como primeira língua, a língua de sinais e a língua portuguesa, como segunda língua, na modalidade escrita.

A mesma lei estabeleceu que fossem garantidas formas de apoiar o uso e a difusão da LIBRAS em todo Brasil. Especificou que o sistema educacional garantisse a inclusão do ensino da LIBRAS nos cursos de formação de Educação Especial, Fonoaudiologia e de Licenciatura em seus níveis médio e superior. O decreto dispôs sobre a formação do professor e do instrutor de LIBRAS, da formação do tradutor e intérprete, da garantia do direito à educação e à saúde das pessoas com surdez (BRASIL, 2005).

Esses dispositivos legais encontram respaldo científico de autores da área que afirmam que a criança deve aprender como língua materna, a língua brasileira de sinais e como segunda, a língua portuguesa (QUADROS, 1997; 2008; FERNANDES, 1990; SKLIAR, 1998). Ainda nesse sentido, Quadros (2002) contribui dizendo que: "Quando me refiro ao bilinguismo, não estou estabelecendo uma dicotomia, mas sim reconhecendo as línguas envolvidas no cotidiano dos surdos, ou seja, a Língua Brasileira de Sinais e o Português no contexto mais comum do Brasil.” (2000, p.54).

Portanto, o aluno Surdo tem direito de receber uma educação bilíngue de qualidade, seja nas escolas de educação bilíngue ou na escola regular. E, quando ela acontecer na escola regular, é importante atentar-se a colocação de Werneck (2003, p. 35):

O conceito de inclusão nos ensina não a tolerar, respeitar ou entender a deficiência, mas sim a legitimá-la, como condição inerente ao 'conjunto humanidade'. Uma sociedade inclusiva é aquela capaz de contemplar sempre, todas as condições humanas, encontrando meios para que cada cidadão, do mais privilegiado ao mais comprometido, exerça o direito de contribuir com seu melhor talento para o bem comum.

Vale destacar o que aponta a Declaração de Salamanca (1994):

[...] todas as escolas deveriam acomodar todas as crianças, independentemente de suas condições físicas, intelectuais, sociais, emocionais, linguísticas ou outras. Deveriam incluir todas as crianças [...] deficientes e superdotadas, crianças de rua e que trabalham, crianças de origem remota ou de população nômade, crianças pertencentes a minorias linguísticas, étnicas ou culturais e crianças de outros grupos em desvantagem ou marginalizados. As escolas têm que encontrar a maneira de educar com êxito todas as crianças, inclusive as que têm deficiências grave (UNESCO, 1994, p. 19)

Tais afirmativas permitem que a reflexão de que apenas o acesso e matrícula do aluno PAEE como prática de inclusão é errônea e deve ser superada. Deve-se oferecer ensino e

\footnotetext{
${ }^{1}$ Skliar (1998) traz marcada em seus livros a distinção de "surdo", com "s" minúsculo e "Surdo", com "S" maiúsculo. Klein (2001:88) diz que na língua inglesa encontramos com frequência essa distinção. "O termo surdo refere-se ao fator físico da surdez, enquanto o termo Surdo refere-se ao grupo cultural e à comunidade linguística”. Essa distinção será utilizada no presente trabalho.
} 
aprendizagem adequados e adaptados quando necessário, para que a participação desse aluno seja plena e verdadeiramente efetiva nos objetivos precípuos da escola. Karnopp e Pereira (2003) afirmam que para compreender uma proposta educacional para Surdos é importante a clareza de que o indivíduo se constitui através da Língua e que a Língua natural dos Surdos é a Língua de Sinais. Logo, essa proposta educacional para eles precisa estar embasada no Bilinguismo. Quadros (2005, p.27) diz que ao estarmos inseridos na sociedade participamos de diferentes línguas em diferentes circunstâncias e cenários, dentro disso o Bilinguismo pode ser considerado: o uso que as pessoas fazem de diferentes línguas (duas ou mais) em diferentes contextos sociais.

Neste trabalho, atenta-se para a importância da aprendizagem e aquisição da língua de sinais para o Surdo, desde sua primeira infância e no contexto da escola bilíngue. Vygotsky (2001) diz que a linguagem é fundamental na formação dos processos mentais, e a língua, além de ser uma forma de comunicação, é uma função reguladora do pensamento. Ela proporciona a transmissão de conceitos e sentimentos, além de promover a ampliação dos conhecimentos. Logo, o aluno surdo pode ter o bloqueio da linguagem verbal, mas isso não impede seu desenvolvimento nos processos não-verbais. Diante disso, fica nítido que quanto antes a criança Surda ter acesso à língua de sinais, melhor ela se desenvolverá. A aquisição da língua de sinais desde a primeira infância torna-se indispensável para a construção do pensamento sendo a escola o principal (e muitas vezes único) ambiente onde esse contato irá acontecer.

Levando em conta as afirmativas suscitadas pela temática da inclusão do aluno Surdo e do Bilinguismo o presente trabalho tem por objetivo principal verificar a importância da aprendizagem e aquisição da língua de sinais para o aluno Surdo no contexto da escola bilíngue.

\section{REFERENCIAL TEÓRICO}

\section{A importância da aquisição da língua}

O ser humano utiliza a língua e a linguagem com a finalidade de comunicar-se. No entanto, não se pode excluir outras formas de comunicação que são utilizadas por humanos e outros seres vivos, que não utilizam a língua e/ou a linguagem verbal, tais como: os animais comunicam-se entre si, transmitindo informação para os membros de sua espécie; o bebê que se comunica através do choro suas necessidades. Em ambos os casos citados, está presente uma comunicação. Entretanto, de acordo com a Hormann (1972, citado por LOPES, 2008, p. 29): 
[...] a linguagem dos animais não é um produto cultural (a cultura é tipicamente humana). Essa linguagem não é senão um componente da organização físicobiológica das abelhas (por exemplo) herdada por programação genética da espécie. A linguagem humana, por seu lado, não é herdada: o homem aprende a sua língua. Em segundo lugar, a linguagem dos animais é invariável, no tempo e no espaço. Ela fornece sempre, ao mesmo grupo, o mesmo tipo de informação (alimento, por exemplo). Por outro lado, a comunicação dos animais é composta de índices (isto é, de um dado físico ligado a outro dado físico por uma relação de causalidade); ela não se compõe, ao contrário da nossa, de signos que nascem das convenções feitas pelo homem, e onde o significado é diferente da substância material que o expressa. Isso significa que a comunicação animal não é articulada, isto é, não é suscetível de ser analisada em unidades mínimas.

E para aprender a língua é necessário interagir com o meio. Para que aconteça uma comunicação eficaz é necessária a língua. E, para aquisição da língua, é preciso interação com o outro, ou seja, com o meio. De acordo com Vygosty (1934/1999), o desenvolvimento humano dá-se com a interação entre o meio sócio histórico cultural e o homem. São com as interações que surgem os conflitos, que o indivíduo percebe o mundo, constrói conceitos, reorganiza ideias, numa dinâmica dupla de transformar o meio e ser transformado por ele, num transformar-se recíproco e dialético. A teoria de Vygosty, que é sócio interacionista, também estuda a linguagem e seu papel no desenvolvimento cognitivo. Vygosty $(1989, \mathrm{p} .45)$ afirma que "o uso de signos conduz os seres humanos a uma estrutura específica de comportamento que se destaca do desenvolvimento biológico e cria novas formas de processos psicológicos enraizados na cultura". Por isso, o meio social contribui e compromete o desenvolvimento e aquisição da língua. Transferindo essa conotação para o tema em questão, pode-se afirmar que se a criança Surda está inserida em um contexto bilíngue, seja na escola ou na família, isso facilitará seu aprendizado.

Saussure (1969) afirma que a língua é um "sistema de signos", ou seja, um conjunto de unidades que estão organizadas, formando um todo, sendo o signo associação entre significantes (imagem acústica) e significado (conceito). Ele também define a língua como parte determinada da linguagem, essencial dela. Lopes (1977) aponta que as línguas são como um produto das convenções e dos valores sociais de onde derivam as regras que tornam compreensíveis as intercomunicações dos indivíduos e asseguram a sobrevivência e coesão das sociedades. Assim, compreende-se com essas afirmações que a língua é fundamental para o desenvolvimento cognitivo, conhecimento de mundo e evolução do pensamento.

Compreende-se que a língua é um conjunto de elementos que possibilitam a comunicação e é imprescindível para o desenvolvimento do pensamento. A linguagem, por sua vez, desenvolve e compreende a língua e outras manifestações, tornando-se essencial nas relações. Dentro do contexto língua de sinais existe a possibilidade de a pessoa Surda não 
adquirir a língua, seja de sinais ou portuguesa, mas através de gestos simples e caseiros, desenvolver uma linguagem para uma comunicação superficial.

Rodrigues Moura (2008, p.17), baseado em Vygosty (1934/1999), diz que a linguagem é a ferramenta psicológica mediadora das relações entre os indivíduos e o mundo, responsável pela organização do pensamento, pelas conceitualizações das mais simples às mais

complexas. É por meio dela que o homem se apropria do legado cultural construído pela humanidade. A linguagem e as construções de pensamento realizadas por meio dela são o que diferencia o ser humano dos animais, permitindo uma série de transformações e vivências, aquisição de novos conceitos, planejamento de ações e a construção das mais variadas representações. As ações humanas ganham intencionalidade, e o desenvolvimento das funções psicológicas superiores propiciam o controle sobre nós mesmos.

Baseados nos conceitos abordados, os processos de mediação nas quais as crianças surdas de famílias ouvintes estão inseridas podem ser insuficientes falhos, pois as mesmas não participam ativamente da língua utilizada naquele contexto (oral) e isso pode causar um atraso no desenvolvimento global (RODRIGUES-MOURA, 2008).

Dentro desse contexto, a aprendizagem não se dá da mesma maneira para todos, as crianças surdas filhas de famílias ouvintes, até conhecerem a Língua de Sinais, estabelecem uma comunicação limitada, muitas vezes por meio de gestos inventados/convencionados no seio familiar ou de mímicas. Nesses casos, os surdos constroem uma linguagem, porém de forma deturpada por estarem solitariamente nesse processo (RODRIGUES-MOURA, 2008).

Para que a criança surda, filha de pais ouvintes, não tenha prejuízos em seu desenvolvimento global, é preciso que, o quanto antes ela adquira e utilize a Língua de Sinais (que é sua língua materna), pois isso possibilitará comunicação, interação, construção de conceitos, desenvolvimento da língua e da linguagem que auxiliará na construção do pensamento verbal (RODRIGUES-MOURA, 2008). Ser membro de uma sociedade é estar inserido, participando ativamente. Isso só é possível quando é proporcionado que o conhecimento alcance a todos.

\section{Libras e o Bilinguismo como proposta educacional para Surdos}

Baseada na Língua de Sinais Francesa foi desenvolvida a Língua Brasileira de Sinais (GESSER,2009). A LIBRAS, diferente do que muitos pensam não é composta de mímicas e gestos, ela possui uma estrutura gramatical própria. Os sinais, sua unidade básica, são formados com movimento das mãos e de pontos de referência no corpo ou no espaço. 
As línguas de sinais são, portanto, consideradas pela linguística como línguas naturais ou como um sistema linguístico legitimo, e não como um problema do surdo ou como uma patologia da linguagem. Stokoe, em 1960, percebeu e comprovou que a língua de sinais atendia a todos os critérios linguísticos de uma língua genuína, no léxico, na sintaxe e na capacidade de gerar uma quantidade infinita de sentenças. (QUADROS; KARNOPP, 2004, p. 30)

A Lei 10.436 de 2002 (BRASIL, 2002) reconhece o estatuto linguístico da Língua de Sinais e, ao mesmo tempo assinala que esta não pode substituir o português. Porém, os surdos ainda se sentem excluídos dessa sociedade, citando-se como exemplo o depoimento de uma mulher com surdez mencionado em Skliar (1998, p.59):

É neste sentir-se rejeitado em comunicação que nos faz sentir-nos mal em família. Não há um sentir-se igual. É impossível ser feliz num clima desses. É o exílio do silêncio a que estamos sujeitos. Sujeitos a sermos devotados aos ouvintes e sem esperanças... Eu percebo, é claro que a minha vida deve ser feita em outro grupo, com os surdos. Angústia é este sentimento. É preciso reconquistar o espaço que nos tiraram. $\mathrm{Na}$ verdade, é uma perda angustiante. Nossa presença entre ouvintes não é legal ( $R$, surda de 30 anos).

Percebe-se que a língua é fundamental para o desenvolvimento humano e que, além de permitir a comunicação, ela proporciona construção do pensamento e conhecimento de mundo. Já que a pessoa Surda não tem acesso à língua portuguesa na modalidade oralauditiva, por não ouvir, a língua de sinais torna-se essencial para que ele se desenvolva como indivíduo ativo e participante na sociedade.

Para falarmos de proposta educacional para Surdos é importante a clareza de que o indivíduo se constitui através da Língua e que a Língua natural dos Surdos é a Língua de Sinais. Logo, uma proposta educacional para eles precisa estar embasada no Bilinguismo.

Quadros (2006, p.27) diz que ao estamos inseridos na sociedade participamos de diferentes línguas em diferentes circunstâncias e cenários, dentro disso o Bilinguismo pode ser considerado: o uso que as pessoas fazem de diferentes línguas (duas ou mais) em diferentes contextos sociais.

Contudo, no caso do Bilinguismo para Surdos há algo imprescindível que deve ser observado, é o fato da diferença de modalidade, pois a língua utilizada pelos ouvintes é oralauditiva, já os Surdos é viso-espacial. Por isso, pensar em Bilinguismo para Surdos, no mínimo, deve ser considerado o que aponta Quadros (2006): "Este contexto bilíngue é completamente atípico de outros contextos bilíngues estudados, uma vez que envolve modalidades de línguas diferentes". E ainda, FERREIRA-BRITO (1993, p.53, 65) afirma que: 
modalidade diferente, cada uma em situações distintas. A língua dos sinais será usada em todas as situações em que uma língua materna é usada nas escolas, exceto no que se refere à escrita e à leitura, onde ela pode ser o meio, mas não o objetivo. A língua oral será ensinada enquanto segunda língua e será o veículo de informação da tradição escrita.

Vale ressaltar que toda língua carrega em si um teor cultural, portanto, ao falarmos de Bilinguismo que pressupõe a aquisição de duas línguas ou mais, tenho que considerar que esse indivíduo circulará entre as culturas. Nesse caso, o convívio e o ambiente proporcionará o desenvolvimento na aquisição de uma segunda língua. Por exemplo, se uma criança de origem inglesa que convive num ambiente que se utiliza inglês britânico, se desenvolverá com lentidão na aquisição de uma segunda língua.

Nesse prospecto que se encaminham as discussões sobre a criança Surda ter acesso à língua de sinais na primeira infância. Assim como a criança ouvinte nasce e recebe inúmeros estímulos, a criança Surda tem o direito a uma comunicação, para que seu desenvolvimento não seja comprometido.

\section{A importância da aquisição da língua na primeira infância}

E, se existe a língua de sinais, ela é reconhecida e ofertada as pessoas Surdas, quais são os embates que dificultam o acesso e/ou aprendizagem da pessoa com surdez? Para ilustrar, apresentam-se algumas questões que ao longo dos anos foram levantadas pelos estudiosos e pesquisadores. A primeira trata de uma discussão no processo de ensino aprendizagem, e especificamente na primeira infância, a alfabetização. Skliar (2001) disserta sobre essa necessidade de alteração nas concepções já desenvolvidas pelos ouvintes e aponta que o problema não é a surdez, não são os surdos, não são as línguas de sinais, mas, as representações que os ouvintes criaram acerca da surdez. Logo, isso tem que mudar, para que o processo de alfabetização da criança surda seja um processo prazeroso e satisfatório.

Outro fator que dificulta esse processo é o fato da maioria das crianças Surdas, serem filhos de pais ouvintes, estima-se que seja noventa por centro. Nesse ambiente, grande parte das famílias não se interessam em aprender a língua de sinais, criam gestos caseiros para uma comunicação diária e simples. E, ainda que nós tenhamos os sentidos naturais, como descrito abaixo, é evidente a necessidade de uma língua para construção do pensamento.

Nascemos com nossos sentidos; eles são "naturais". É possível desenvolvermos sozinhos, naturalmente, as habilidades motoras. Mas não podemos adquirir sozinhos uma língua: essa capacidade insere-se numa categoria única. Não se pode desenvolver uma língua sem alguma capacidade inata essencial, mas essa capacidade só é ativada por uma outra pessoa que já possui capacidade e competências linguísticas. É somente por meio de transação (ou, como diria 
Vygotsky, "negociação") com outra pessoa que a linguagem é desenvolvida. (SACKS, 2010, p.59)

Para que esse processo tenha sucesso, é necessário a interação com o outro e nesse ponto, destaca-se a importância do ambiente bilíngue e a aquisição da língua de sinais desde cedo. Porém, lidamos com os reveses sociais, que Santana (2007, p.22) aponta como cobranças aos Surdos, que acarretam prejuízos:

Surge uma série de dicotomias quando discutimos o tema surdez, e estas refletem as diferentes posições que os surdos têm de tomar diante da impossibilidade de ouvir. Não são posições tomadas ao acaso, tampouco são ideologicamente neutras. Elas estão relacionadas com os conflitos e as pressões sociais que os surdos enfrentam na sociedade ouvinte: deficiente/diferente; cultura surda/cultura ouvinte; normalidade/anormalidade; linguagem oral/ língua de sinais.

É nesse contexto que fica claro que a criança surda sofre um entrave já que costuma ter contato com a língua tardiamente, no ensino fundamental, por volta dos cinco a seis anos de idade. Essa triste condição, acarreta atrasos no desenvolvimento cognitivo e social. Sacks (2010, p.53) aponta uma discussão antiga, mas que ainda permeiam os anseios atuais, desde 1915 o neurologista inglês Hughlings Jackson já afirmava que a língua deveria ser adquirida o mais cedo possível; caso contrário, seu desenvolvimento seria retardado e prejudicado, com todos os problemas ligados à capacidade de proposicionar.

Para minimizar esses problemas e/ou diminuir as possibilidades de comprometimento na aprendizagem da criança Surda, uma importante orientação dos profissionais, seria os pais aprenderem a LIBRAS, assim a criança estaria em um ambiente bilíngue, se desenvolveria com as situações vivenciadas, adquiriria leitura de mundo, se sentiriam incluídas, seres participantes e ativos numa família e na sociedade.

\footnotetext{
Por não terem pessoas proficientes com quem se comunicar, os surdos deixam de vivenciar todos os usos efetivos da linguagem. Muitos pais acabam por utilizar sinais para informar, e não para comentar, explicar, contar histórias, contar piadas. Isso pode ter implicações significativas, como atraso na aquisição da língua de sinais e, consequentemente, atraso cognitivo (considerando-se a inter-relação entre linguagem e cognição), impossibilitando de se constituir-se um sujeito falante e exclusão social do surdo (SANTANA, 2007, p.117).
}

Atualmente sabe-se que grande parte das famílias não tem clareza dessa importância (FERREIRA, 2008). Quando buscam ajuda, algumas vezes ouvem que a oralização seria a melhor opção, já que se vive em uma sociedade ouvinte. Isso faz com que não conheçam a língua de sinais e desconheçam a importância de aprendê-la e ensiná-la seu filho surdo, desde cedo (FERREIRA, 2008). 
Sacks (2010, p.38) aponta a importância da aquisição da língua de sinais para crianças desde cedo:

\begin{abstract}
As crianças surdas precisam ser postas em contato primeiro com pessoas fluentes na língua de sinais, sejam seus pais, professores ou outros. Assim que a comunicação por sinais for aprendida- e ela pode ser fluente aos três anos de idade-, tudo então pode decorrer: livre intercurso do pensamento, livre fluxo de informações, aprendizado da leitura e escrita e, talvez, da fala. Não há indícios de que o uso de uma língua de sinais iniba a aquisição da fala. De fato, provavelmente ocorre o inverso.
\end{abstract}

É a aquisição de uma língua, e nesse caso a LIBRAS, que proporcionará condições da criança Surda se desenvolver, constituindo o funcionamento cognitivo, afetivo, conhecimento de mundo, estabelecer suas relações interpessoais, expandir suas potencialidades. A língua de sinais dará condições de construir o pensamento, dando significados ao mundo. Goldfeld (2002, p.116) nos mostra que a educação baseada no bilinguismo parte do diálogo, como ocorre com crianças ouvintes, possibilitando a internalização da linguagem e o desenvolvimento das funções mentais superiores.

Com isso, o direito de aprender desde cedo, ter contato com a comunidade Surda, aprender a língua de sinais, devem ser garantidos para que ocorra o desenvolvimento pleno, sem danos. Proporcionando a essa criança, a oportunidade de ser feliz, de um sentimento de completude, independência e autonomia.

\title{
PERCURSO INVESTIGATIVO
}

\section{Universo da pesquisa}

Esta pesquisa tem natureza qualitativa com delineamento de estudo de caso. Segundo Ludke e André (1986, p. 17), o estudo de caso:

[...] é sempre bem delimitado, devendo ter seus contornos claramente definidos no desenrolar do estudo. O caso pode ser similar a outros, mas é ao mesmo tempo distinto, pois tem um interesse próprio, singular. $\mathrm{O}$ interesse, portanto, incide naquilo que ele tem de único, de particular, mesmo que posteriormente venham a ficar evidentes certas semelhanças com outros casos ou situações.

Esse tipo de investigação, produz um conhecimento amplo e não um objetivo imediato. Os resultados não buscam uma abrangência universal, como outras metodologias propõem.

A pesquisa foi desenvolvida em uma EMEBS - Escola Bilíngue para Surdos da Prefeitura de São Paulo. A escola atende alunos do Ensino Fundamental I e II, nos três turnos: manhã, tarde e noite. Todos os alunos da escola são Surdos, porém existem alunos com múltiplas deficiências, atualmente contando com 176 alunos matriculados. A pesquisa 
aconteceu em sala de aula, durante as aulas de Língua Portuguesa. O número de alunos varia de acordo com a turma, mas a média é de no mínimo sete e máximo quinze.

Quadro 1 - Caracterização das salas de aula observadas

\begin{tabular}{|l|l|l|l|}
\hline \multicolumn{1}{|c|}{$\begin{array}{c}\text { NÍVEL DE } \\
\text { ENSINO }\end{array}$} & \multicolumn{1}{c|}{$\begin{array}{c}\text { MÉDIA DE ALUNOS } \\
\text { PRESENTES }\end{array}$} & \multicolumn{1}{c|}{$\begin{array}{c}\text { PERÍODO } \\
\text { OBSERVADO }\end{array}$} & \multicolumn{1}{c|}{ AULA } \\
\hline $\begin{array}{l}\text { Fundamental -6 } \\
\text { (EJA) }\end{array}$ & Oito & Noturno & $\begin{array}{l}\text { Língua } \\
\text { Portuguesa }\end{array}$ \\
\hline $\begin{array}{l}\text { Fundamental- } \\
\text { (EJA) }\end{array}$ & Onze & Noturno & $\begin{array}{l}\text { Língua } \\
\text { Portuguesa }\end{array}$ \\
\hline
\end{tabular}

\section{Participantes}

Foram observadas duas turmas que cursam o Ensino Fundamental, uma do sexto ano e outra do oitavo ano, ambas da Educação de Jovens e Adultos, no período noturno. Todos os alunos são Surdos. A faixa etária varia entre 18 a 40 anos. Cada turma tem em média dez alunos. A professora tem 42 anos de idade, formação em Letras, com especialização em Educação Especial e em Libras. Atua no magistério há nove anos e na educação de Surdos há seis.

\section{Instrumentos}

O instrumento utilizado para coletar os dados foram roteiros de observações, em turmas e momentos diferentes, todos durante as aulas de língua portuguesa, conforme descrito no Quadro 1. Utilizou-se também um questionário com oito perguntas abertas, enviado via correio eletrônico para a professora de língua portuguesa, cujas aulas foram observadas.

\section{Procedimentos para a coleta de dados}

As informações foram coletadas a partir dos registros de observações realizadas durante os estágios nos meses de maio, agosto e setembro de 2016, durante as aulas de língua portuguesa. Ao todo foram realizadas 20 horas de observações e respondido pela professora um questionário com oito questões.

\section{Procedimentos para a análise de dados}

Os dados observados e registrados no roteiro de observação foram analisados a partir da relação com a fundamentação teórica da pesquisa, sendo apresentados de forma descritiva. Em relação ao questionário, a análise dos dados foi realizada levando em consideração a 
análise proposta por Bardin (2011). A análise temática trata de um feixe de relações e pode ser graficamente apresentada através de uma palavra, frase ou resumo, a partir de uma préanálise e leitura analítica para categorizar os itens de acordo com a semelhança temática e textual.

\section{Procedimentos Éticos}

Esta pesquisa está vinculada ao Projeto Integrado de Pesquisa "Educação Especial na Perspectiva da Educação Inclusiva: política educacional, ações escolares e formação docente", aprovada pelo Comitê de Ética em Pesquisa, da Faculdade de Filosofia e Ciências (FFC), UNESP, campus de Marília e cadastrada na Plataforma Brasil sob o $\mathrm{n}^{\text {o }}$ 64353216.6.0000.5406, cujo parecer é de $n^{\circ}$ 1.939.831 datado de 23 de fevereiro de 2017.

\section{RESULTADOS E DISCUSSÕES}

Os resultados apresentados abordam inicialmente a configuração física e dinâmica da sala de aula e da escola. Após isso são apresentadas práticas pedagógicas utilizadas pela professora participante, apresentação da rotina de sala de aula e a análise das respostas ao questionário.

As salas de aula observadas são formadas por grupos de no máximo onze alunos, as organizações das carteiras são em forma de "u" para que todos possam ter acesso visual à professora e aos colegas. Na escola observada todas as professoras utilizam Libras para comunicar-se com os alunos. Na sala de aula há murais com espaços para expor os trabalhos desenvolvidos. As aulas são organizadas a cada 45 minutos, em alguns dias há dobras de disciplina. A sala de leitura tem um acervo bem vasto.

A professora de português trabalhou escrita e utilizou além do quadro branco, materiais impressos com os sinais em Libras. Realizaram-se vinte horas de observações, divididas em cinco encontros. Sendo dois encontros na sala do sexto ano e três no oitavo ano. A professora acompanhada demonstrou ser paciente e usou a Libras o tempo todo. Explicava as atividades em Libras e depois passava a lição na lousa, em língua portuguesa. Sempre perguntava se os alunos tinham dúvidas e quando elas surgiam, ela buscava o maior número de exemplos para que o aluno compreendesse. Apresentou à pesquisadora algumas atividades diferentes, especificamente para Libras e para as turmas com mais dificuldades. No entanto, essas atividades não estavam disponíveis em grande quantidade e também não contemplava todas as séries. Em uma das aulas observadas a professora utilizou um livro, contou a história 
em Libras e depois usou o flipchart para anotações e solicitar uma atividade específica. Os alunos compreenderam a proposta e desenvolveram a atividade.

Nesse momento, percebe-se que a professora cumpre o que se pede na lei 10.436 de 2002 (BRASIL, 2002) que reconhece o estatuto linguístico da Língua de Sinais e, ao mesmo tempo assinala que esta não pode substituir o português. Na mesma aula, ela ensinou Libras para os alunos que ainda não são fluentes, explicando em Libras eles aumentam o vocabulário e ensinou a língua portuguesa na modalidade escrita. Mas, sempre usando a língua nativa do Surdo, para explicar e realizar as mediações. Cumprindo exatamente o que está disposto no decreto, já citado nessa pesquisa.

No sexto ano, a primeira turma observada é composta por alunos que estão ingressando agora, então, embora eles estejam no sexto ano do ensino fundamental, eles ainda estavam em processo de alfabetização. Alguns nunca tinham ido à escola e não sabiam a língua de sinais. Foram aprender Libras ali e ainda estavam sendo alfabetizados na língua portuguesa. Esses alunos que não tiveram acesso à língua de sinais, vivendo até aquele momento com sinais caseiros criados para uma comunicação simples, são os alunos que mais demonstraram dificuldades de aprendizado.

Nesse contexto, a primeira pergunta feita a professora foi "na sua opinião, a partir de que idade a criança surda deve começar a frequentar a escola? A resposta da professora entrevistada foi: "Desde a educação infantil, acredito que quanto antes estiver no ambiente escolar melhor será seu desenvolvimento".

Baseado nessa observação e na experiência da professora, afirma-se o que Sacks (2010, p.53) aponta que a língua deveria ser adquirida o mais cedo possível; caso contrário, seu desenvolvimento seria retardado e prejudicado, com todos os problemas ligados à capacidade de proposicionar. E ainda, Guarinello (2007, p.48) reitera:

(...) para que as crianças surdas venham adquirir a língua de sinais como primeira língua, é necessário que elas sejam expostas a usuários competentes dessa língua, ou seja, adultos surdos fluentes, que vão responder tanto pela exposição como pelo ensino da gramática para as crianças e seus pais, que, em $95 \%$ dos casos, são ouvintes.

O que reafirma a observação, comparando esses alunos ingressantes com alunos matriculados, já inseridos no contexto escolar e no uso da língua de sinais, o prejuízo por falta de língua é bem evidente.

Nas demais turmas observadas, os alunos são alfabetizados em língua portuguesa na modalidade escrita, sabem Libras, embora alguns também só a adquiram ali na escola. Com esses alunos a professora trabalhou bastante interpretação de texto e verbos. Segundo a 
professores eles têm bastante dificuldade em conjugar verbos e isso eu já tinha observado, até com a escrita de professores Surdos que tive em minha primeira especialização. No entanto, o que os estudos apontam é que o quanto antes a criança ter acesso à língua de sinais, a possibilidades dessas dificuldades permearem a vida adulta, serão menores.

Perguntado "Com base em sua experiência, como a criança Surda desenvolve noções de leitura e escrita? A professora respondeu: "Primeiramente através das imagens que trabalhamos em sala, sempre fazendo a relação da mesma com seu sinal correspondente. Outro recurso importante é o contato com os livros, seu manuseio e a exploração das imagens e sinais e após com a palavra escrita correspondente, Professora. E ainda, na terceira pergunta “Quais os métodos têm sido utilizados para a alfabetização de Surdos?”, "Buscamos fazer um ambiente no qual a criança tenha contato com o mundo da escrita, com cartazes, listas e claro, muitas imagens. Todo material que produzimos necessita de imagem, junto ao seu sinal, primeiramente. O alfabeto, por exemplo, é sempre apresentado nas duas versões em Libras e no seu correspondente em Língua Portuguesa, Professora.

Pode-se observar a conexão dessa experiência, com as afirmações de FERREIRABRITO (1993, citado por FINAU, 2006, p.12) “Os surdos, devido à falta de audição, requerem educação especial bilíngue. O tipo de bilinguismo é o diglóssico, isto é, o uso em separado de duas línguas, mesmo que de modalidade diferente, cada uma em situações distintas.” Então, ao pensar na educação de Surdos, não basta propor que ele tenha acesso à língua de sinais, mas que na escrita também seja considerado o fato de ser um bilinguismo diferente, pois são línguas de modalidades diferentes. Uma língua é oral auditiva, enquanto a outra é visual espacial.

A quarta pergunta trata-se do ambiente familiar para a pessoa Surda, que vem de encontro com a observações realizadas, no que se refere aos sentimentos daqueles alunos. Todos demonstram interesse, aquele lugar para eles, parece mais do que uma escola, é uma oportunidade de eles serem eles mesmos e usarem a língua de sinais. Porém, pelo fato de terem entrado tardiamente na escola e sem língua alguma, alguns demonstram bastante dificuldade. Então realizamos o seguinte questionamento "Qual a importância da família no processo de alfabetização da criança Surda? E de que forma estes podem colaborar para melhoria do mesmo? Sua resposta foi: "A melhor contribuição que a família pode dar à criança Surda é aprender LIBRAS para poder manter uma comunicação efetiva com os filhos. Sabemos que os familiares são os que primeiro nomeiam o mundo para a criança e, no caso dos Surdos isso acontece de uma forma muito difícil, já que grande parte dos pais não buscar aprender sinais. Dessa forma, quando a criança chega à escola não tem uma língua materna 
desenvolvida nem minimamente. O que essas crianças têm são sinais "caseiros", criados na família para solucionar questões básicas. A família que ao descobrir que seu filho é Surdo vai em busca de curso para aprender a Língua de Sinais, proporciona à criança um grande aprendizado, melhora a vivência familiar e potencializa o desenvolvimento de um modo geral” (Professora). A fala da professora denota o que Sacks (2010, p. 59) diz:

\begin{abstract}
Nascemos com nossos sentidos; eles são "naturais". É possível desenvolvermos sozinhos, naturalmente, as habilidades motoras. Mas não podemos adquirir sozinhos uma língua: essa capacidade insere-se numa categoria única. Não se pode desenvolver uma língua sem alguma capacidade inata essencial, mas essa capacidade só é ativada por uma outra pessoa que já possui capacidade e competências linguísticas. É somente por meio de transação (ou, como diria Vygotsky, "negociação") com outra pessoa que a linguagem é desenvolvida.
\end{abstract}

E como observou-se, os Surdos fazem desse ambiente, a escola bilíngue, parte da sua família e contexto social, explicitando as necessidades desses educandos através da fala dos estudiosos, bem como das experiências do corpo docente, verificamos a importância de eles estarem inseridos em um ambiente educacional que proporcione além de aprendizagem, conhecimento de mundo.

A professora mencionou que eles não estudam em casa. Só estudam na escola e que isso prejudica o desenvolvimento e aquisição da língua e conceitos. Mesmo quando há uma preocupação por parte do corpo docente, como ficam claras nas questões cinco e seis, vejamos: "Quantas às atividades elaboradas há alguma especificidade no caso do Surdo, ou as atividades são as mesmas aplicadas para as crianças ouvintes? Ela disse "As atividades elaboradas para os Surdos precisam de adaptações, pois são crianças visuais, dessa forma, as atividades precisam de imagens aliadas à Língua de Sinais, Professora. Na questão seguinte, verifica-se a fala da professora interagindo com os teóricos desse artigo, já que durante todo processo apontamos a importância do ensino da língua de sinais como primeira língua. Observem "De que forma a Libras contribui para o processo de alfabetização?” Ela discorre “A Libras é a língua materna da pessoa Surda, sendo assim, a criança que tem a Libras já internalizada consegue aprender a Língua Portuguesa como L2 de maneira muito mais simples, pois já possui um sistema linguístico da L1. A Libras é imprescindível para a alfabetização da criança, já que todo seu pensamento é baseado na mesma, Professora. Notase que a língua de sinais permeia todas as relações, já que utilizamos a língua para o convívio social. Com isto, afirma-se o objetivo desse artigo, o bilinguismo estar presente em todas as etapas da vida da pessoa Surda e especialmente desde à primeira infância. 
Na sétima questão, reforça-se a importância da aquisição da língua de sinais, desde a primeira infância. "Como que se comunica a maioria das pessoas Surdas quando chegam à escola, eles já estão inteirados na Libras ou não?” Ela responde de forma concisa "Infelizmente grande parte dos alunos chegam à escola sem a Libras, pois como já dito, nas famílias há pouco interesse em aprender a língua. Assim a escola se constitui como espaço privilegiado para esses alunos que terão com quem trocar experiências, ideias, sentimentos e desenvolver sua língua materna, Professora. E sem conhecimento dos registros de observações, nota-se a interligação das ideias e das experiências, já que foram registradas que a escola bilíngue é um excelente espaço de desenvolvimento, aquisição de língua e conhecimento de mundo. Os surdos sentem-se à vontade. Trocam experiências, demonstram interesse nas atividades, mesmo quando estão com dificuldades. Consideramos que esse formato seja mantido, mesmo que existam outras propostas pedagógicas e de inclusão. $\mathrm{O}$ Surdo deve ter o direito de escolher de que forma ele quer aprender e estar.

Verificou-se que quando há mais alguma deficiência atrelada, ou seja, o aluno não tem apenas a surdez, o processo de aprendizagem torna-se mais difícil e a aquisição da língua e dos conceitos torna-se lentos. E isso acontece com frequência. A famílias não buscam orientação médica, acham que pelo fato da criança não ouvir, é deficiente auditivo e se satisfazem com esse diagnóstico, sem procurar verificar se há outras deficiências atreladas ou até mesmo algum outro transtorno. Sem laudo médico, esses alunos sofrem prejuízo educacional, pois nesses casos não se trata apenas da surdez, mas outras decorrências de dificuldades da deficiência desse aluno. Ainda assim, se ele estiver matriculado na escola bilíngue, ele pode frequentar as aulas, participar como qualquer aluno, independente da deficiência e falta de laudo. Porém, nesses casos, seriam necessários outros estudos para apontar as decorrências de ações como essas.

Para encerrar o estudo de caso, na questão oito, trata-se de o Surdo estar inserido em uma escola especializada, escola bilingue, que foi motivo de lutas durante muito tempo na comunidade Surda. Essa defesa partiu deles, que são os principais interessados nesse contexto. E a professora tem experiência na escola regular e na especializada. Vejamos suas colocações: "Em sua opinião os Surdos deveriam frequentar escola regular ou uma escola especializada para Surdos?" Ela diz: "Eu trabalho em uma escola regular e em uma escola especializada para Surdos e, na minha opinião de longe a escola para Surdos é muito melhor para eles. Na escola regular ainda não há uma estrutura que inclua realmente os Surdos. Na escola especializada o aluno consegue se comunicar com todos, encontra seus pares e se desenvolve muito e, estar em uma escola bilíngue não significa segregação e sim acesso 
verdadeiro ao conhecimento, à língua, significa oportunidade real. A interação e integração com o mundo ouvinte acontecerá naturalmente se o Surdo tiver uma L1 bem trabalhada, aliado ao conhecimento da Língua Portuguesa na modalidade escrita, mas mais que isso, se ele tiver sua autoestima fortalecida e se reconhecer como sujeito de direito e não como uma pessoa que fica à margem, excluída dentro da própria escola e, esse trabalho de reconhecer-se como sujeito acontece de forma muito importante na escola especializada, Professora.

Nesse contexto, pode-se dizer que eliminaríamos o sentimento que Skliar (1998, p.59) mostra de uma Surda de 30 anos "É neste sentir-se rejeitado em comunicação que nos faz sentir-nos mal em família. Não há um sentir-se igual. É impossível ser feliz num clima desses. É o exílio do silêncio a que estamos sujeitos...”. Silva (2006, p. 46) aborda sobre essa questão:

\begin{abstract}
Os problemas dos surdos com a aquisição da escrita estão mais relacionados aquisição e ao desenvolvimento de uma língua efetiva que lhes permita uma identidade sociocultural, ou seja, estar insertos no contexto social; só assim poderão entender as diferenças existentes entre sua própria língua e as outras.
\end{abstract}

Como podemos conviver com o sentimento de que existem pessoas que não sabem o significado da palavra "consciência"? Durante as observações, dentre tantos os fatos, um nos chamou mais a atenção. Um aluno perguntou à professora sobre determinado sinal e ela respondeu o significado. Em seguida, ele indagou sobre o significado daquela palavra, que nesse caso é "consciência”. A professora usou vários exemplos para explicar o que significa consciência e enfim, ele compreendeu. Mas, nota-se, esse aluno tem aproximadamente trinta anos de idade e passou todo esse tempo na escuridão, sem conhecimento. Isso é decorrente do fato de não ter língua. E quantos outros Surdos existem nessa mesma condição? Diante disso, é imprescindível um ambiente bilingue, que priorize as especificidades da pessoa Surda.

Além disso, o que fica muito claro é que o quanto antes o Surdo ingressar na escola, maior desenvolvimento na aprendizagem e aquisição da língua ele terá. Percebemos que alunos com faixa etário média entre 18 e 22 anos, que já conhecem e dominam a língua de sinais, porém saíram da escola por inúmeros motivos e estão retornando agora, conseguem comunicar-se, expressar-se, compreendem os conceitos e aprendem com mais facilidade. Já os alunos, com faixa etária avançada, que não tiveram acesso à língua de sinais cedo e no contexto familiar a comunicação era a combinação de gestos caseiros, ou seja, não pessoas que não tinham uma língua, utilizavam-se apenas de linguagem, tem dificuldade em adquirir a língua e consequentemente aprender. 


\section{CONSIDERAÇÕES FINAIS}

No presente estudo de caso, produziu-se um estudo sobre "A importância da língua de sinais para o aluno Surdo na educação bilíngue”, com objetivo de averiguar a aquisição da língua de sinais para o aluno Surdo no contexto da escola bilíngue.

A escola deve receber, acolher e proporcionar uma educação de qualidade a todos, inclusive o aluno com deficiência. Dentro desse contexto e baseado na lei 10.436 de 2002, que reconhece a Libras como a Língua Brasileira de Sinais, afirma que é a segunda língua oficial do Brasil e a língua natural do Surdos brasileiros. Eles deverão aprender como primeira língua, a língua de sinais e como segunda língua, a língua portuguesa na modalidade escrita.

De acordo com as observações realizadas e as respostas da professora, que também foram analisadas se relacionando com a fundamentação teórica, percebe-se a importância que o Surdo tenha acesso a língua o mais cedo possível, ele precisa estar em um ambiente bilíngue para que possa adquirir uma língua, desenvolver-se e ser um membro participante e ativo no mundo, sem língua, a linguagem torna-se rasa, e algumas vezes deturpada. É necessário a língua e o bilinguismo para o que o Surdo tenha condições de se desenvolver, proporcionando uma vida digna e uma educação de qualidade.

Algumas limitações acerca desse estudo foram a ausência de referencial teórico publicado nos últimos três anos apresentando estudos relacionados e também a impossibilidade de obter mais informações sobre os alunos por conta do delineamento do estudo.

\section{REFERÊNCIAS}

BRASIL. Ministério da Educação. Secretaria de Educação Especial. Política Nacional de Educação Especial. Brasília: MEC/SEESP, 1994.

Ministérios da Educação. Diretrizes nacionais para a educação especial na educação básica / Secretaria de Educação Especial - MEC; SEESP, 2001. 79p.

Lei $\mathrm{n}^{\circ}$ 10,436, 24 de abril de 2002. Dispõe sobre a Língua Brasileira de Sinais LIBRAS e dá providências. Brasília, DF, 24 de abril de 2002.

Decreto $\mathrm{n}^{\circ} 5,626$, de 22 de dezembro de 2005. Regulamenta a Lei $\mathrm{n}^{\circ} 10,436$, de 24 de abril de 2002, que dispõe sobre a Língua Brasileira de Sinais - LIBRAS, e o art. 18 da Lei n 10,098 , de dezembro de 2000. Brasília, DF, 22 de dezembro de 2005.

FERNANDES, E. Surdez e bilinguismo. Porto Alegre: Mediação, 2005.

FERREIRO-BRITO, L. Integração social \& educação de Surdos. 2. ed. Rio de Janeiro: Babel, 1993. 
FINAU, R. Possíveis encontros entre cultura, surdez, ensino e linguística. In: QUADROS, R.M. (org.). Estudos surdos I. Petrópolis: Arara Azul, 2006.

GESSER, A. LIBRAS?Que língua é essa?: crenças e preconceitos em torno da língua de sinais e da realidade surda. São Paulo: Parábola Editorial, 2009.

GOLDFELD, Márcia. A criança surda: linguagem e cognição numa perspectiva sóciointeracionista. $2^{\mathrm{a}}$ ed. São Paulo: Plexus, 2002.

KARNOPP, L. A língua na educação de surdos. v.2. Porto Alegre: Secretaria da Educação/Departamento Pedagógico/Divisão de Educação de Especial, 2005.

LACERDA, C. A inclusão escolar de alunos surdos: O que dizem alunos, professores e intérpretes sobre esta experiência. In: Educação Surdez e Inclusão social. Caderno CEDES 69 Vol.1, São Paulo: Cortez, 2006.

LOPES, E. Fundamentos da Linguística Contemporânea. 20. ed. São Paulo: Cultrix, 1977.

QUADROS, R .M.; KARNOPP, L. Língua de sinais brasileira: estudos linguísticos. ArtMed: Porto Alegre, 2004.

QUADROS, R.M. Educação de surdos: a aquisição da linguagem. Porto Alegre: Artes Médicas; 1997.

. Alfabetização e o ensino da língua de sinais. Textura, Canoas n.3, 2000.

2006.

.Estudos surdos I / Ronice Müller de Quadros (org.). - [Petrópolis, RJ]: Arara Azul,

.Estudos surdos III / Ronice Müller de Quadros (org.). - [Petrópolis, RJ]: Arara Azul, 2008.

RODRIGUES-MOURA, D. O uso da LIBRAS no ensino de leitura de Português como segunda língua para Surdos: um estudo de caso em uma perspectiva bilíngue. Dissertação (Mestrado em Linguística Aplicada e estudos da linguagem)- Universidade Católica de São Paulo, São Paulo, 2008.

SACKS, O. Vendo vozes: uma viagem ao mundo dos surdos. Tradução Laura Teixeira Motta. São Paulo: Companhia das Letras, 2010.

SANTANA, A. P. Surdez e linguagem: aspectos e implicações neurolinguisticas. São Paulo: Plexus, 2007.

SAUSSURE, Ferdinand de. Curso de linguística geral. Trad. de A. Chelini, José P. Paes e I. Blikstein. São Paulo: Cultrix; USP, 1696.

SILVA, V. Educação de Surdos: uma releitura da primeira escola Pública para surdos em Paris e do Congresso de Milão em 1880. In: QUADROS, Ronice Muller de. (Org.). Estudos Surdos I. Petrópolis, RJ: Arara Azul, 2006.

SKLIAR, C. Surdez: um olhar sobre as diferenças. Porto Alegre: Dimensão, 1998. 
UNESCO. Declaração de Salamanca e linha de ação sobre necessidades educativas especiais. Brasília: UNESCO, 1994

VYGOTSKY, L.S. Formação social da mente. 2. Ed. São Paulo: Martins Fontes , 1934/1999.

Pensamento e linguagem. 2. Ed. São Paulo: Martins Fontes , 1989.

A construção do pensamento e da linguagem. São Paulo: Martins Fontes, 2001. Tradução de Paulo Bezerra.

WERNECK, C. Você é Gente? O direito de nunca ser questionado sobre seu valor. Rio de Janeiro. WVA, 2003.

WILCOX, S. WILCOX, P.P. Aprender a ver. Editora Arara Azul, 2005. 